\title{
BACHELARD E BENJAMIN: A CRÍTICA LITERÁRIA AO LAUTRÉAMONT
}

\author{
Gabriel Kafure da Rocha \\ Bárbara Canto
}

\section{RESUMO}

O presente trabalho tem como proposta fazer uma investigação sobre as possibilidades de conexões interpretativas entre Bachelard e Benjamin. Em "Magia e técnica, arte e política", logo no primeiro capítulo, Walter Benjamin se propõe a analisar o surrealismo a partir de 1929 por meio de suas origens, entre elas, "Les chants de Maldoror" (publicada originalmente em 1868) a obra de Lautréamont, pseudônimo de Isidore Ducasse, estudante uruguaio de matemática que viveu na França e, ao que consta, enloqueceu e escreveu essa obra que descreve um estado de violência poética chocante para a época. Em 1939, Gaston Bachelard escreveu a sua primeira obra de crítica literária, Lautreámont. Nela, o autor identifica essa violência descrita como um dos aspectos que move a razão. Desse modo, Bachelard a classifica como uma poesia nervosa cujo bestiário revela complexos da cultura e sua animalidade. Em 1940, pouco antes da morte de Benjamin, mais precisamente no dia 23 de Março, Benjamin envia uma carta a Horkheimer onde em grande parte, faz uma análise crítica do livro de Bachelard. Nesse sentido, realizamos uma leitura crítica do valor surreal e surracional de Lautréamont como impulso necessário para leituras interpretativas da experiência de produzir semelhanças da transmissibilidade histórica da contemporaneidade.

Palavras-chave: Surrealismo. Surracionalismo. animalidade. Devaneio. Imaginação.

\section{BACHELARD ET BENJAMIN: LA CRITIQUE LITTÉRAIRE AU LAUTRÉAMONT}

\section{RESUME}

Cet article vise à étudier les possibilités de liens interprétatifs entre Bachelard et Benjamin. Dans "Magie et technique, art et politique", au premier chapitre, Walter Benjamin analyse le surréalisme de 1929 à ses origines, notamment "Les chants de Maldoror" (initialement publié en 1868) pour Lautréamont, pseudonyme d'Isidore Ducasse, étudiant uruguayen en mathématiques et résidant en France, serait devenu fou et aurait écrit cet ouvrage qui décrit un état de violence poétique choquante à l'époque. En 1939, Gaston Bachelard a écrit son premier ouvrage de critique littéraire, "Lautreámont ", dans lequel l'auteur identifie cette violence décrite comme l'un des

Doutor em Filosofia pela Universidade Federal do Rio Grande do Norte (UFRN). Prof. De Filosofia do Instituto Federal do Sertão Pernambucano. Colombiano/Brasileiro, Residente em Petrolina - PE. Email:

Gabriel.rocha@ifsertao-pe.edu.br

Doutoranda em Filosofia pela Universidade Federal do Paraná (UFPR). Brasileira. Residente em João Pessoa - PB. Email: barbynascimento@gmail.com 
aspects qui font bouger la raison. Ainsi, Bachelard se classe comme une poésie nerveuse dont le bestiaire révèle des complexes de culture et de son animalité. En 1940, peu avant la mort de Benjamin, plus précisément le 23 mars, Benjamin envoie une lettre à Horkheimer dans laquelle il analyse en grande partie le livre de Bachelard. En ce sens, nous effectuons une lecture critique de la valeur surréaliste et surréaliste de Lautréamont en tant qu'élément nécessaire à la lecture interprétative de l'expérience de production de similitudes dans la transmissibilité historique de la contemporanéité.

Mots-clés: Surréalisme. Surrationalisme. I'animalité. Rêverie. Imagination.

\section{Introdução}

"A poesia deve ser feita por todos, não por um."

(LAUTRÉAMONT, 2005, 312).

A crítica enquanto auto referência, como a crítica de si, é algo já presente nos Les Chants de Maldoror, ali, na medida em que se observam paráfrases, paródias, plágio, metalinguagem e colagens, pode-se dizer que tudo isso está arremessando a crítica literária para o futuro, como uma grande hibridez de tudo o que já foi feito, na acumulação deformante de tudo que será feito. Hybris, essa palavra que atormentava os gregos, provavelmente pelo medo do anormal e da deformação, é aqui, o nosso principal tema de crítica que nos leva ao surrealismo e consequentemente ao debate imaginário acerca de Lautréamont entre Benjamin e Bachelard.

Para Benjamin, em "Mágia e técnica, arte e política" (1987), o capítulo "O surrealismo: o último instantâneo da inteligência europeia" foi baseado, por sua vez, em um artigo publicado em 1929 na revista Literarische Welt, um periódico semanal importante na República de Weimar. Benjamin se identifica com o caráter revolucionário do movimento de vanguarda francesa, a ideia da colagem e montagem, e o seu caráter

Doutor em Filosofia pela Universidade Federal do Rio Grande do Norte (UFRN). Prof. De Filosofia do Instituto Federal do Sertão Pernambucano. Colombiano/Brasileiro, Residente em Petrolina - PE. Email:

Gabriel.rocha@ifsertao-pe.edu.br

Doutoranda em Filosofia pela Universidade Federal do Paraná (UFPR). Brasileira. Residente em João Pessoa - PB. Email: barbynascimento@gmail.com 
de insurreição como o "Manifesto do Surrealismo" de 1924, um movimento que se utilizava das ideias de Freud e as possibilidades híbridas das imagens do inconsciente.

O surrealismo é fruto do contraste entre imaginação e valorização da poesia, tem como grandes influências Baudelaire, Rimbaud, Apollinaire e Lautréamont. Esse último é o que mais nos interessa, porque as experiências iniciais do surrealismo tivessem um caráter semelhante ao romantismo. Em Lautréamont nasce um tipo de simbolismo totalmente insurgente, revoltante, marginal e diferente.

Bachelard e Benjamin são dois filósofos que podem ser considerados marginais, ambos viveram no contexto em que a psicanálise havia revolucionado a maneira de enxergar o inconsciente. Bachelard de um lado, procura se distanciar de Freud e vê em Jung um caminho mais aberto para o imaginário. Benjamin por outro lado, em seu escopo filosófico, trata de conceitos muito caros a Freud, conceitos que foram e são até hoje muito importantes para o universo psicanalítico, contudo, ambos parecem ter a desilusão de não encontrar nesse caminho psicanalítico a força e ímpeto estético que o surrealismo conseguiu por meio da arte.

Já Isadore Ducasse, que aderiu ao pseudônimo de Lautréamont, um uruguaio que nasceu próximo da região do Prata, filho de um embaixador francês em Uruguai, foi mandado pelo pai de volta ao velho mundo, para que encontrasse sua disciplina acadêmica pela matemática. Profundamente decepcionado, Isadore Ducasse encontra no imaginário da animalidade, a nobreza de seu personagem, Lautréamont, que adentra no inferno de Maldoror e sob a forma de um vampiro, um monstro demasiado humano, é atacado animalmente por Maldoror. Contudo, é como se Maldoror quisesse rejeitar esse monstro com ar de sábio, vampiresco, jovem filósofo, sanguessuga.

\section{Benjamin e surrealismo}

Alguns esclarecimentos acerca de elementos que surgem no ensaio sobre o surrealismo são de extrema importância para entender o que Benjamin chama, "último

Doutor em Filosofia pela Universidade Federal do Rio Grande do Norte (UFRN). Prof. De Filosofia do Instituto Federal do Sertão Pernambucano. Colombiano/Brasileiro, Residente em Petrolina - PE. Email:

Gabriel.rocha@ifsertao-pe.edu.br

Doutoranda em Filosofia pela Universidade Federal do Paraná (UFPR). Brasileira. Residente em João

Pessoa - PB. Email: barbynascimento@gmail.com 
instante da inteligência europeia". Sonho e embriaguez são termos que se tem sempre em mente ao se deparar com as críticas feitas ao movimento surrealista. Nesse sentido, entender como funcionam dentro do movimento é crucial.

A vida só parecia digna de ser vivida quando se dissolvia a fronteira entre sono e vigília, permitindo a passagem em massa de figuras ondulantes, e a linguagem só parecia autêntica quando o som e a imagem, a imagem e o som se interpenetravam, com exatidão automática, de forma tão feliz que não sobrava a mínima fresta para inserir a pequena moeda a que chamamos "sentido". (BENJAMIN, 1987, 22)

É nesse estado onde a plena potencialidade onírica aliada ao instante do realizável, que a vigília oferece, que se encontra o surrealismo, onde o "sentido" se torna coadjuvante e a linguagem se transforma num uníssono de imagem e som permitindo assim, a realidade se tornar algo experiencial. Linguagem essa que Benjamin assinala como tendo precedência na construção e assimilação de conhecimentos.

Sonho, esse elemento tão trabalhado na literatura psicanalítica, adquire em Benjamin um sentido diferente daquele utilizado por Freud e seus sucessores. Para o primeiro, o sonho é o momento pelo qual o instante, quer seja histórico, ou não, que carrega consigo a potência de reestruturar o contexto a que se está exposto, pode ser recordado e através do despertar ser rememorado e ressignificado. Assim, entre outros conceitos, Benjamin, descreve o surrealismo. O novo que traz em seu bojo a oportunidade de ressignificar o presente por meio da releitura do passado através do sonho, tem no despertar o momento pelo qual a ação se tornará possível.

Assim, prosseguindo na explanação, enquanto o sonho é o remédio contra a individualidade, uma vez que, durante seu período é a linguagem quem conduz o poeta, e assim, abala o seu Eu, a embriaguez seria por seu turno, o momento de experienciar a realidade tal qual ela não se manifesta, mas a quem está a ela aberta para vivê-la. Benjamin ainda aponta que esse estado influenciado por agentes condutores de realidades paralelas (sonho, embriaguez), não seria o único modo de exercício para o surrealismo: "é um grande erro supor que só podemos conhecer das experiências

Doutor em Filosofia pela Universidade Federal do Rio Grande do Norte (UFRN). Prof. De Filosofia do Instituto Federal do Sertão Pernambucano. Colombiano/Brasileiro, Residente em Petrolina - PE. Email: 
surrealistas os êxtases religiosos ou os êxtases produzidos pela droga", a verdadeira apreensão do conceito surrealista estaria em sua "iluminação profana de caráter materialista e antropológica" (BENJAMIN, 1987, 22), ou seja, na iluminação profana, por que é feita por nossas próprias ações acerca das condições materiais, concretas em que a humanidade se desenvolve..

Como dito logo acima, iluminação aqui não tem a mesma acepção que tem no sentido religioso. Essa iluminação não se deve a nenhuma interferência divina, e aí está seu caráter materialista, é através da própria experiência e dos conhecimentos acerca do humano que levariam autor e leitor a iluminação e, por conseguinte, a compreender o surrealismo. Assim, entendemos a importância dos conceitos de experiência e memória, que recebem um lugar muito especial em seus textos, serem mais uma vez utilizados pelo autor ao falar da autêntica apreensão da proposta surrealista:

Um caso construtivo de experiência reveladora. Cenário desta revelação é a memória. Experiências vividas reveladas não nos ocorrem como uma revelação, mas permanecem escondidas de quem as experimenta. Tornam-se revelação apenas nos olhos voltados para o passado; como muitos tomam consciência deles por analogia. É encontrada aqui uma diferença importante da revelação religiosa. (BENJAMIN, 2010, 224)

A memória (essa que conduz também os sonhos) seria, portanto, o fio condutor que nos liga a experiências passadas e, que irrompe de maneira inesperada, mas com tal alcance que permite uma apreensão do presente de maneira a transformá-lo. De maneira análoga, temos o termo, revelação, que por sua vez, precisa ser dissociado de seu uso mais corrente, ou seja, o da revelação religiosa (e aqui podemos encaixar também a revelação produzida por drogas) que não possui o mesmo alcance produzido pela revelação tida por aqueles que se valem de experiências vividas que se ligam à memória. Dessa forma, encontramos a grande diferença que tem aqueles tipos de revelação (o religioso) para o sentido que este termo adquire no movimento surrealista, dentro da interpretação benjaminiana.

Doutor em Filosofia pela Universidade Federal do Rio Grande do Norte (UFRN). Prof. De Filosofia do Instituto Federal do Sertão Pernambucano. Colombiano/Brasileiro, Residente em Petrolina - PE. Email:

Gabriel.rocha@ifsertao-pe.edu.br

Doutoranda em Filosofia pela Universidade Federal do Paraná (UFPR). Brasileira. Residente em João Pessoa - PB. Email: barbynascimento@gmail.com 
Dando prosseguimento aos esclarecimentos das inspirações tidas por Benjamin para a composição deste ensaio, destacamos um autor que foi identificado por ele como grande inspiração para o movimento surrealista: Rimbaud e seu Saison en Enfer, apontados por Benjamin como o autor e a obra que deram impulso ao movimento:

O satanismo pertence aos elementos fundamentais da experiência surrealista. Deve-se pensar na adoração com a qual os surrealistas falam do Marquês de Sade, no [certamente: terceiro] canto em Lautréamont, na cena no Théàtre des deux masques descrito por Breton]. (BENJAMIN, 2010, 224)

Assim, através do que ele chamou de questão do mal ${ }^{1}$, ele demarca a ligação entre Lautréamont e Rimbaud, "Se Rimbaud é a pilha de madeira em chamas, Lautréamont é o jogo de vento com suas cinzas. (BENJAMIN, 2010, 217)". O mal, e por sua vez, o satanismo, é por Benjamin considerado o elemento que permite a ligação de Lautréamont ao surrealismo. O mal é considerado por ele como fator importante contra o proselitismo moral da época, uma vez que possuiria a força de arrancar a perniciosa ação da moralidade do campo da política, no sentido de que, seria a "adoração ao mal: uma arma, mesmo que romântica, na batalha contra moralidade na política" (BENJAMIN, 2010, 216). Na sequência, uma citação que Benjamin em seus apontamentos atribui a Lautreámont e que nos permite demonstrar a aproximação do mal lautreamontiano ao surrealismo:

Deixe-me primeiro explicar a você minha situação. Eu cantei o mal como fizeram Mickiewicz, Byron, Milton, outhey, Musset, Baudelaire, etc. Naturalmente, exagerei no diapasão para criar algo novo no sentido dessa literatura sublime que canta desespero apenas para oprimir o leitor, e para fazêlo desejar o bem como remédio. Então, é sempre o bem que cantamos em suma, apenas por um método mais filosófico e menos ingênuo do que a velha escola, incluindo Victor Hugo e alguns outros são os únicos representantes que ainda estão vivos. (LAUTRÉAMONT apud BENJAMIN, 2010, 225)

\footnotetext{
1 Nos apontamentos feitos por Benjamin para a construção do artigo do surrealismo, ele expõe o problema do mal, do qual ele deriva o satanismo.

Doutor em Filosofia pela Universidade Federal do Rio Grande do Norte (UFRN). Prof. De Filosofia do Instituto Federal do Sertão Pernambucano. Colombiano/Brasileiro, Residente em Petrolina - PE. Email: Gabriel.rocha@ifsertao-pe.edu.br

Doutoranda em Filosofia pela Universidade Federal do Paraná (UFPR). Brasileira. Residente em João Pessoa - PB. Email: barbynascimento@gmail.com
} 
Agora, fazendo a ligação entre Bachelard e Benjamin, mais precisamente na leitura que faz de Bachelard, Benjamin considera que este reivindica para Lautréamont, o lugar de avô do surrealismo,

Bachelard indica o papel preponderante que joga as bestas no papel da imaginação de Lautréamont. $O$ autor elabora um inventário de formas animais que abundam em Les Chants de Maldoror. Não seria, além disso, a forma elástica dos animais que consistiria a assombração do poeta, mas a forma e o esforço de sua vontade agressiva. Aqui, novamente, a apresentação de Bachelard parece inatacável. Ele explica o quanto Lautréamont se preocupou com as diferentes formas de agressão animal. (BENJAMIN, 2016, 131)

Essas formas de agressão se transformam e se transfiguram umas nas outras, como uma metamorfose sem fim da animalidade. Lautréamont parece ter predileção pelas criaturas que voam e nadam, provavelmente por terem mais relação com o conceito metafísico de espírito.

Benjamin fornece algumas referências para nos aprofundar no Lautréamont de Bachelard citando trechos marcantes de sua obra como:

- "Fenomenologia essencialmente dinâmica";

É curioso que a palavra fenomenologia aparece mais no início do livro, já a palavra dinâmica está mais ligada a psicologia, contudo, ao falar de uma fenomenologia dinâmica, a fenomenologia é colocada em relação à agressão e à crueldade. Especificamente no trecho em que fala da fenomenologia essencialmente dinâmica, Bacelar se refere à relação entre a garra e a pata na multiplicidade orgânica do ataque.

- "Psiquismo não só cinético, mas realmente potencial";

Nesse trecho, Lautréamont consegue escapar à fatalidade com segurança de seus atos, pela experiências das ações suspensas e ameaças adiadas de Maldoror.

- "o animal é uma psiquê monovalente";

Essa afirmação está no contexto de que a psicologia do animal está submetida a um determinismo vital, o animal não é uma máquina, mas é o jogo de uma animalidade maquinada. "O instinto é uma monomania e toda a monomania descobre um instinto específico. A maneira mais rápida de descrever a aberração humana é compará-la com

Doutor em Filosofia pela Universidade Federal do Rio Grande do Norte (UFRN). Prof. De Filosofia do Instituto Federal do Sertão Pernambucano. Colombiano/Brasileiro, Residente em Petrolina - PE. Email:

Gabriel.rocha@ifsertao-pe.edu.br

Doutoranda em Filosofia pela Universidade Federal do Paraná (UFPR). Brasileira. Residente em João Pessoa - PB. Email: barbynascimento@gmail.com 
um comportamento animal. O animal é um psiquismo monovalente" (BACHELARD, $1989,111)$

Nesse sentido, Benjamin encara de uma maneira tanto Isadore Ducasse quanto o próprio Bachelard, indicando que ambos estão realmente interessados pelo aspecto cômico de tal surrealidade. A severidade da obra Chants de Maldoror está mais no caráter revoltado do "estudante" Ducasse em relação à matemática, e essa severidade é uma psicose profissionalizada pela figura do professor.

O último aspecto, que segundo Benjamin escapa ao próprio Bachelard, é que ele deixa um sonho/devaneio considerado como o "platonismo da violência" (BACHELARD, 1989, 108). Bachelard acredita que essa é a filosofia que está por vir, Benjamin já desvela essa acepção como o sonho de ação política, pelo qual há ameaça, imprevisibilidade e a luta contra a igualdade na diferença contra uma mesmidade elegida pela força o que é, em última instância, nada menos do que a imagem de Hitler, para o filósofo alemão. Refletindo se isso teria a ver com a relação entre o lautréamontismo, entendemos que essa ambiguidade é intocada no nãolautréamontismo, apesar de fazer parte da originalidade de sua interpretação benjaminiana, de alcançar o cunho político da crítica literária, o que pode se encaixar perfeitamente na atualidade. A valorização da obscuridade de uma obra como Les chants de maldoro, nos leva a clarear os valores desumanos mais bestiais.

\section{Bachelard e Lautréamont}

Para Lautréamont, é necessário especificar que, se Les chants de Maldoror foi publicado pela primeira vez em 1869, é a partir dos anos trinta que serão reeditados na França e graças aos surrealistas. Observe que em seu artigo da Nouvelle Revue Française de 1939, que é o início de seu Lautréamont, que aparecerá no ano seguinte, Gaston Bachelard faz referência à edição de 1938 de Jose Corti editeus, que será o editor de Lautréamont de Bachelard, também é desde 1926, o dos surrealistas, de sua livraria Rua de Clichy, que então instalou a margem direita do rio. (POULIQUEN, 2007, 99)

Gaston Bachelard é conhecido por inaugurar uma nova crítica literária depois de ter publicado o livro Lautréamont, constando como o Novo Espírito Literário, diferente Doutor em Filosofia pela Universidade Federal do Rio Grande do Norte (UFRN). Prof. De Filosofia do Instituto Federal do Sertão Pernambucano. Colombiano/Brasileiro, Residente em Petrolina - PE. Email:

Gabriel.rocha@ifsertao-pe.edu.br

Doutoranda em Filosofia pela Universidade Federal do Paraná (UFPR). Brasileira. Residente em João Pessoa - PB. Email: barbynascimento@gmail.com 
das obras sobre os elementos, que classificam a manifestação literária pela ligação do fenômeno literário ligado aos elementos como fogo, água, terra ou ar. Em Lautréamont, a abertura de Bachelard se dá para a imagem. O que os críticos indicam em comum entre Lautréamont e as obras sobre os elementos é a chamada psicanálise da imagem, o que de fato leva a essa tendência é o contato direto de Bachelard com os poetas surrealistas, sendo influenciado especialmente por Caillois, como descreve Thierren:

Em 1938, R. Caillois, em "O Mito e o homem" citado por Bachelard em Lautreamont (p 143 sq.), Afirmou ( 181, nota 1) que o estudo sério dos "Chants de Maldoror" ainda não foi realizado. É de outro, por R. Caillois, em setembro de 1934, que Bachelard realmente conhecia os poetas e o movimento surrealista; Surrealista até 1936, R. Caillois falou muito a Bachelard sobre d'Eluard, Lautréamont, Char, Breton, Aragon, etc. Foi ele quem, após este reencontro, no qual houve uma doença de Paul Langevin e uma "Conferência internacional de filosofia" (em Praga) foram a oportunidade, enviada a Bachelard "Les Chants of Maldoror", acompanhada de alguns escritos de Eluard e outros surrealistas. Foi, portanto, por R. Caillois que Bachelard tomou posse dos Chants de Maldoror, que ele começou a se ocupar em 1934. (THERRIEN, 1970, 44)

O ponto psicanálitico que Bachelard encontra nos Les Chants de Maldoror é efetivamente partir para a raiz do problema e não atacar as manifestações do inconsciente, de modo a colocar em causa nossos hábitos, retórica e nossa própria estética tradicional. O curioso dessa constatação é justamente que Les chants não tem como objetivo seduzir o leitor, mas sim desordenar lentamente o sistema de nossa imaginação, dinamizando para deformação de nossas imagens.

É importante frisar que a psicanálise da obra não é um psicologismo do autor. Lautréamont nos convida a fazer essa distância da psicanálise clássica, na medida em que é impossível reduzir a obra aos elementos da vida de seu autor. A obra deve ser uma totalidade autônoma, um livro-vivo, que ganha vida na medida em que é ela mesmo uma fenomenologia.

Lautréamont representa uma violência simbólica revoltada contra toda convenção. Bachelard entende que nessa obra há uma imaginação animalizante, o primeiro capítulo da obra descreve o élan entre o músculo e o nervo na animalidade lautréamonteana. As metamorfoses nas visões monstruosas são confrontadas com as Doutor em Filosofia pela Universidade Federal do Rio Grande do Norte (UFRN). Prof. De Filosofia do Instituto Federal do Sertão Pernambucano. Colombiano/Brasileiro, Residente em Petrolina - PE. Email: Gabriel.rocha@ifsertao-pe.edu.br

Doutoranda em Filosofia pela Universidade Federal do Paraná (UFPR). Brasileira. Residente em João Pessoa - PB. Email: barbynascimento@gmail.com 
alucinações fantasmagóricas, do que Bachelard chama de complexo lautréamonteano, que é, nada menos que a própria psicanálise da vida que coloca o bestiário como um arquétipo, aonde várias imagens podem ser criadas e interpretadas. ${ }^{2}$

A tortura e a monstruosidade de Lautréamont representam a ânsia de liberdade, essa força imaginativa da primitividade da consciência no embate do mundo concreto e material. O leitor desses versos sente a estranheza, a exclusão do mundo cotidiano, sente-se, na verdade, entrando num pesadelo ou num verdadeiro delírio. Essa sensação carrega uma impressão de deja vue, na medida em que tal mergulho consiste também num reencontro com a nossa interioridade, das experiências recônditas de nossa sombra, ou mesmo, com uma iminência do absurdo, aquilo que beira, ou é, senão, a própria irracionalidade da vontade.

Nisso, Marly Bulcão pontua que:

O querer-viver de Schopenhauer é uma forma de irracionalismo, de passividade que só se impõe pela massa, pela quantidade e pela totalidade, já que está presente em todo o universo. A vontade Lautréamontista, ao contrário, é um querer-atacar, dramático e incerto, que pode ser encontrado na dualidade dos instintos erótico e agressivo, trazendo, portanto, a marca paradoxal da alegria e do sofrimento. A vontade de atacar ducassiana faz com que a trajetória do movimento se torne uma fibra, um nervo, um músculo. Mais uma vez, a ideia de materialidade e de imaginação material aparece como pressuposto fundamental do poema, revelando todas as nuanças do complexo animal que marcam o querer-atacar ducassiano. (BULCÃO, 2003, 44).

Essa garra representa uma multiplicidade orgânica, pela qual o instinto de agressão comanda o poema, renegando símbolos e imagens aprendidas, regatando o corpo e deformando-o como a meta de descrição do instinto. Provavelmente a estranheza e a ambiguidade desse empreendimento, se liga, de certa forma, ao que

\footnotetext{
2 "Jung nos dá um vislumbre da síntese do complexo e da sublimação. De fato, os "complexos" são centros do dinamismo psíquico, precisam das imagens para se manifestar. As imagens variam nos acontecimentos do complexo, mas em vez das imagens de uma psicologia superficial, que poderiam ser fugazes e contingentes, aparecem [então imagens] profundamente enraizadas na psique humana. As imagens também têm uma hierarquia e Jung, num sentindo maior, elucidou a obscuridade desta hierarquia para encontrar as imagens fundamentais, aquelas que estão vivas tem todas as idades, em todos os homens de diferentes etnias e culturas. Estas são as que ele chama de arquétipos conhecidos pela imaginação." (BACHELARD apud ROCHA, 2019, 99 - grifos do autor).
}

Doutor em Filosofia pela Universidade Federal do Rio Grande do Norte (UFRN). Prof. De Filosofia do Instituto Federal do Sertão Pernambucano. Colombiano/Brasileiro, Residente em Petrolina - PE. Email: Gabriel.rocha@ifsertao-pe.edu.br

Doutoranda em Filosofia pela Universidade Federal do Paraná (UFPR). Brasileira. Residente em João Pessoa - PB. Email: barbynascimento@gmail.com 
Benjamin constatará de sua interpretação, como o que Bachelard descreve como o "não-lautréamontismo'. Bachelard entende que isso representa a própria superação do lautréamontismo como uma poesia pura, criadora, que alcança a liberdade plena, é aí que está a soma infinita das potencialidades de estar entre um sur-animal e um surhomem, de modo que um não negue o outro e nos leve ao êxtase da existência.

Nesse sentido, do ir "além" do animal e do homem, Bachelard traz a proposta de ir além não só da realidade (surreal), mas também da própria racionalidade enquanto surracionalidade. De fato, Bachelard cria esse neologismo numa época de transição entre suas fases epistemológicas e poética, e indica que esse é um elo de ligação tanto da ciência quanto da arte: a agressividade. André Breton enfatiza essa intenção ao dizer que

É neste sentido que devemos admitir que o surrealismo é necessariamente acompanhado por um surracionalismo que é um duplo e uma medida. A recente introdução pelo Sr. Gaston Bachelard no vocabulário científico da palavra surrationalisme que aspira a realizar todo um método de pensamento, empresta uma adição tópica e força à palavra surrealismo, cujo significado até então permaneceu estritamente artístico. Novamente um dos dois termos verifica o outro: esta constatação é suficiente para colocar em evidência o espírito comum, fundamental que impulsiona o homem a pesquisar hoje, quer se trate de poeta, pintor ou cientista. (BRETON, 1936, 35).

Nos parece assim que essa iniciativa que nasceu com a crítica literária de Bachelard, toma corpo com esse novo conceito que vai realmente além dos aspectos artísticos para se tornar uma forma crítica de criar novas formas de pensamento.

\section{CONCLUSÃO}

A intenção deste trabalho foi, além de apresentar duas concepções do surrealismo que, embora tenham uma aproximação em alguns pontos de sua exposição, possuem visões bem distintas em outras. Compreendemos que tal apresentação teve o mérito de ampliar as discussões acerca deste tema e ofereceu também uma leitura que permite vislumbrar outras facetas destes autores tão

Doutor em Filosofia pela Universidade Federal do Rio Grande do Norte (UFRN). Prof. De Filosofia do Instituto Federal do Sertão Pernambucano. Colombiano/Brasileiro, Residente em Petrolina - PE. Email:

Gabriel.rocha@ifsertao-pe.edu.br

Doutoranda em Filosofia pela Universidade Federal do Paraná (UFPR). Brasileira. Residente em João Pessoa - PB. Email: barbynascimento@gmail.com 
interessantes e que ocupam lugares diversos na literatura filosófica. O caráter materialista de Benjamin aliado à concepção fenomenológica de Bachelard num primeiro momento tão distante, encontra no surrealismo um ponto de intersecção que possibilitou a produção deste trabalho e, acreditamos, possibilita a abertura de janelas para que outras facetas destes autores sejam exploradas.

Assim, ainda que possua sua visão filosófica embebida no materialismo dialético, ou talvez exatamente por isso, Benjamin traz uma visão do surrealismo muito aliada a uma crítica de cunho político, e talvez aí se encontre os equívocos de alguma de suas interpretações, mas que de maneira alguma invalida sua percepção do movimento e a interpretação que fez de Bachelard, que aqui foram apresentadas em sua obra Lettres sur Litterature. Tal visão da obra bachelardiana é com certeza um reconhecimento tido por Benjamin da importância que tem Bachelard tanto para a filosofia como para crítica literária, assim como ele próprio buscou ter alguma relevância nesses campos.

Não sabemos se Benjamin encontrou Breton ou outros surrealistas nesta ocasião: nada o indica em sua correspondência. No entanto, parece que, segundo Adorno e Scholem (em seu prefácio a Briefe), ele teria trocado correspondências - hoje "perdidas ou inencontráveis" - com o autor do Manifesto do surrealismo (LÖWY, 2002, 40).

Ainda segundo Löwy, tamanha foi a fascinação de Benjamin pelos surrealistas, que ele procurou se distanciar deles para manter a singularidade de sua obra. Contudo, Rua de mão única foi considerado por outros filósofos, como Ernst Bloch, nada menos como uma obra surrealista. O fato é que nem Benjamin nem Breton utilizaram o conceito de irracional, por serem de certa forma alinhados com a revolta amarga e apaixonada contra a teologia principalmente, por conta da morte nietzscheana de deus/razão.

Já no passo de Bachelard, nota-se que ele pretendeu fazer uma tríplice psicanálise (do surrealismo, da cultura e da vida). Em sua crítica literária iniciada em Lautréamont, ele se utilizou de perspectivas que até então eram inabituais na crítica literária. Passava de uma interpretação que busca a clareza da obra, para ir justamente

Doutor em Filosofia pela Universidade Federal do Rio Grande do Norte (UFRN). Prof. De Filosofia do Instituto Federal do Sertão Pernambucano. Colombiano/Brasileiro, Residente em Petrolina - PE. Email: 
em direção à obscuridade, onde foi possível encontrar a multiplicidade da obra por seus diversos centros de interesse.

É esse aspecto, que em outras palavras, nos faz retomar uma obra como Les Chants de Maldoror em tempos sombrios como vivemos atualmente, e tentar a partir disso, encontrar essa pluriversidade descentralizada da criatividade, pois isso é, em outras palavras, a ontogênese de criar seu próprio tempo. Therrien chama esse impulso de uma fenomenologia morfológica, na qual a animalidade dá vitalidade e velocidade poética fundamental na síncope do plano ontológica da substancialização e animação da obra, que se traduz na palavra sublimação, que é, entre outras palavras, justamente a passagem do animal ao homem.

O que se passa então, é que a descrição da animalidade como aberração, deve tomar uma nova forma, pela qual o reino animal afetivo, seja comparado aos bestiários da Idade Média, e que, em ambos, os valores objetivos são raros, mas a polarização afetiva é preponderante.

Bachelard viu, de fato, desde Lautréamont, que o trabalho é um sistema que carrega em si sua razão de ser cuja coerência por si só define os princípios e normas de sua limpeza. Mas era necessário entender a princípio que toda obra é também elipse, e freqüentemente elipse do essencial; que implica o que a apoia; postulados e axiomas de qualquer tipo que implicitamente assume e cujas críticas devem ser capazes de construir axiomatização. Para esse fim, a psicanálise, as ciências matemáticas e a filosofia têm sido a fonte inspiradora de Bachelard por excelência. (THERRIEN, 1970, 349).

Um último aspecto a ressaltar é que a deformação das imagens deve ser estritamente matemática, Cabe ainda ressaltar que a influência matemática em Bachelard na sua leitura de Lautréamont também traz uma crítica chamada de sintaxe de imagens, pela qual o funcionamento das metáforas é organizado de modo a encontrar a métrica de um poesia projetiva, uma poesia primitiva que cria sua própria linguagem, na medida em que promove uma singularidade que deve se revoltar e se desfazer dos livros e dos mestres. Nisso, Bachelard relembra que o leitor é um co-autor, que a crítica é continuar as metáforas da obra, como ele o fez com Lautréamont, não é reduzir, mas maximizar o potencial delas se apropriando e trazendo-as para seu

Doutor em Filosofia pela Universidade Federal do Rio Grande do Norte (UFRN). Prof. De Filosofia do Instituto Federal do Sertão Pernambucano. Colombiano/Brasileiro, Residente em Petrolina - PE. Email:

Gabriel.rocha@ifsertao-pe.edu.br

Doutoranda em Filosofia pela Universidade Federal do Paraná (UFPR). Brasileira. Residente em João Pessoa - PB. Email: barbynascimento@gmail.com 
mundo, como ele o fez adaptando as imagens de Lautréamont ao seu matematismo. Esse é o papel da imaginação na crítica como um psiquismo precursor de um projeto de uma poesia pura não lautremonteana, que está entre o sur-animal e a superação do homem. É o realismo da irrealidade, ou melhor dizendo, é a constatação de que o real é o irracional, portanto, o surreal é o racional.

\section{REFERÊNCIAS}

BACHELARD, Gaston. Lautréamont. Trad. Maria Isabel Braga. Lisboa: Litoral Edições. 1989.

BENJAMIN, Walter. Magia e técnica, arte e política. São Paulo. Tradução de Sérgio Paulo Rouanet. Brasiliense, 1987.

2010.

Opere complete. Vol III. Trad. Enrico Ganni. Giulio Einaudi Editore. Torino:

. Lettres sur la littérature à Max Horkheimer (1937-1940). Trad. Lukas Barfuss. Paris: Zoe, 2016.

BRETON, André. Crise de l'objet. Cahier d'art. n 11, Paris: 1936

BULCÃO, Marly. Tempo e matéria na poesia visceral de Lautréamont. In_: Cronos, Natal-RN, v. 4, n. 1/2, 39-47, jan./dez. 2003

Bachelard diante do onirismo dinâmico e visceral de Lautréamont.

ALMEIDA, Fábio. Tempo de Lautréamont. Goiânia: Ricochete, 2014.

GATTI, Luciano. Walter Benjamin e o Surrealismo: escrita e iluminação profana. In _: Artefilosofia, Ouro Preto, n. 6, 74-94, Abril de 2009,

LAUTRÉAMONT. Obras completas - O cantos de Maldoror. Trad. de Claudio Willer. São Paulo: lluminuras, 1997.

LÖWY, Michael. Walter Benjamin e o surrealismo: história de um encantamento revolucionário. In _: A Estrela da Manhã. Surrealismo e Marxismo. Rio de Janeiro, Civilização Brasileira, 2002.

Doutor em Filosofia pela Universidade Federal do Rio Grande do Norte (UFRN). Prof. De Filosofia do Instituto Federal do Sertão Pernambucano. Colombiano/Brasileiro, Residente em Petrolina - PE. Email: Gabriel.rocha@ifsertao-pe.edu.br

Doutoranda em Filosofia pela Universidade Federal do Paraná (UFPR). Brasileira. Residente em João Pessoa - PB. Email: barbynascimento@gmail.com 
MANSUY, Michel. «Bachelard et Lautréamont, I : la psychanalyse de la bête humaine ». In_ : Études françaises, vol. 1, n 1, 1965, 26-51.

POULIQUEN, Jean-luc. Gaston Bachelard ou le rêve des origines. Paris:

L'Harmattan, 2007.

ROCHA, G. K.. Bachelard: Estudo Crítico das Causeries ou Lições de Filosofia. 1. ed. Recife: KDP - Independently Published, 2019.

n. 2, 2018.

. Eu grito, logo sou uma energia. In__: Capoeira - Humanidades e Letras. v. 4,

TERNES, José. Bachelard e Lautréamont: Literatura, primitividade, animalidade. In _ : ALMEIDA, Fábio. Tempo de Lautréamont. Goiânia: Ricochete, 2014.

THERRIEN, Vicent. La Révolution de Gaston Bachelard en Critique Littéraire - Ses fondements, ses techiniques, sa portée. Paris: Éditions Klincksieck, 1970.

Doutor em Filosofia pela Universidade Federal do Rio Grande do Norte (UFRN). Prof. De Filosofia do Instituto Federal do Sertão Pernambucano. Colombiano/Brasileiro, Residente em Petrolina - PE. Email: 